\title{
Requirements for the Terminology Definition in the Arabic Lexicons of Critique and Eloquence
}

\author{
Qutaiba Habashneh ${ }^{1}$, Abbas Abbas ${ }^{2}$ \& Ibrahim Rababah ${ }^{1}$ \\ ${ }^{1}$ Language Center, The University of Jordan, Jordan \\ ${ }^{2}$ Arab Open University, Jordan \\ Correspondence: Qutaiba Habashneh, Language Center, The University of Jordan, Jordan. Tel: 962-772443212. \\ E-mail: kotaybayh@yahoo.com
}

Received: Nov. 15, 2018

doi:10.5539/mas.v13n2p1
Accepted: Nov. 28, 2018

Online Published: January 3, 2019

\begin{abstract}
Knowing the status of defining expressions requires the knowledge of the conditions that must occur in this definition to have a full meaning, leading to its original purpose, which also leads to a general agreement about this definition among specialists. The status quo of expressions in dictionaries requires recognition of a set of conditions that govern the definition of an expression in a dictionary a govern the expression itself (connoted and denoted). This study has established some basic conditions. For example, the definition should connote the essence of the item, its gender, division and be equal to the thing it defines. The search for conditions of definition is indeed a search to achieve three purposes: giving the expression its position in the structure of knowledge, agreeing on the specific meaning of the expression, and enabling non-specialists to somehow understand the expression. The research concludes that the general conditions that characterize the definition of expression are clarity, accuracy, and completion.
\end{abstract}

Keywords: critical expressions, rhetorical expressions, definition of expression, critical and rhetorical dictionaries, conditions expression definition

\section{Introduction}

The epistemological analysis of status reality of terminology definition requires understanding its requirements in order to be meaningful enough to lead to the purpose of this terminology placement, hence guiding to a kind of consensus on such definition among scholars, since "such consensus on a specific verb, to denote a particular concept, is not sufficient to conduct a sound critical practice based on understanding. It should be associated with a consensus or at least a preliminary accord on the meaning of such verb. It is true that there is always a pace for dispute and a margin for discussion, even in the western practices from which we acquire these terminology, but there is also another agreement on the minimal level of the meaning of any terminology. There is no way to build up a positive dialogue among scholars without achieving it" (Isteif 1999, p.94).

Such accord is necessary when it comes to the meaning or definition in the lexicon, due to what is supposed to be done by the author or lexicographer to provide the best possible definition of terminology so as to avoid the dilemma of individualism and moodism in dealing with terminologies, besides submitting them to the readers through weird improvisations and judgements, that seem apparently more risky than that what it seem to be as a result of its distorted intellectual arguments and inaccurate cultural content.

Therefore, and based on what has been discussed above, "the optimal approach to address the differences among critics about the meanings of literary and critical concepts is to prepare a critical literary encyclopedia that narrows or reduces the gap of dispute among them, and provides a minimum of common understanding among critics and literature writers and readers" (Isteif 1992, p.141)

But such common understanding requires several indispensable means, when discussing the necessary requirements that should be achieved in the terminological definition within its lexical setting, since its definition outside this framework is controlled by a terminological standard and begins to be free of the lexical criterion, while inside the setting the definition should be controlled by both measures together.

When searching for the requirements of terminological definition within the critical lexicon, we should benefit the efforts of scholars on the requirements of definitions in the linguistic lexicons, such requirements that don't 
represent literal rules in this context rather than representing "general rules that protect the definition from incompetence and obscurity" (Aljelali 1999, p.66).

It seems that the agreement on the requirements of definition differs from one party to another. The rationalists have their own requirements, while the fundamentalists have different requirements, but we find the semantics scholars understand it differently, meanwhile some western linguists reject such argument, since the "meaning of the word is its use by people", as discussed by Wittgenstein. (Zeidan 1985, p.32)

But the status of lexical terminology requires identifying several controls or requirements that mentor the terminological definition in the lexicon after adjusting the terminology itself and protect it from the shortcoming of upset to reach the stability as an indicator and meaning.

Perhaps the strong relationship between lexicographer and his epistemological field, as well as the clarity of the philosophical theory arguments, and " the attentiveness of such field accelerates ,as possible, the achievement of such stability and creates a pace between it and other upset meaningful sounds that reduce the resistance of stable meaningful against the containing of perception" (Jadd , 2002, p.77), so as to obtain a terminology structure, in both internal and external dimensions, that becomes a coherent structure as possible.

This study, which is involved in the terminological definition, identified several basic requirements that don't represent the ultimate condition for lexical definition, but they are proposals that address some aspects and issues of this case. The most important requirements are that the definition should(Aljelali 1999, p.67):

1) Indicate the core of thing.

2) Be the genre and type of thing.

3) Be totally equal to the defined thing.

4) Not define by itself or part of itself.

5) Not define by negative vocabularies.

6) Not mention metaphorical words in the definition.

7) Consist of non-definable primary limits.

As it is clear, some of these requirements can be found in the critical terminology lexicon, while others are not applicable. Such difference urged the researcher to rule, in advance, that any requirements to restrict the definition in constructing the terminological lexicon will not be final, especially in the fields of arts and humanities, while in the scientific terminology context, such requirements may become mandatory in a clearer way, despite such terminology may become more stable than terminologies in other fields of knowledge. The evidence is shown in the findings of contemporary scientists that "selecting symbols indicating things should not be an initial invention, but they should select one characteristic that they consider prevailing among all characteristics. Such selection may due to the worst reason, such as the word of Oxygen where its original meaning is the 'rust maker', while no one had longer been thinking about such meaning after recognizing all characteristics of oxygen, where those people might call it 'life maker' or biogenic if they knew first such characteristic. In fact, the scientists selection of names was not made for a specific reason but as a means to find the word" .(Shahin 1986, p.226).

Nevertheless, the stability of terminology and its meaning is the most important and primary, whether in the fields of science and technology or in the fields of humanities. The search for requirements of definitions in the special terminological theory, within its lexical setting is a quest to achieve three goals and functions as follows:

1) Assign a suitable value for the terminology in the specific epistemological structure. While such process is purely a terminological activity, it is better to call it the terminological definition, because it assumes knowledge of the content of the terminology derived from existed definitions and contexts and consulting the epistemologists.

2) Fix the specific meaning of the terminology, as it is the honest definition used by specialists to determine the exact assignment of such terminology.

3) Enable unspecialized persons to understand the terminology, which refers compulsory to the relevant field of knowledge (Khattabi 1998, p.26).

\section{Definition Requirements}

Here, the search will take us to the necessity of identifying general and large requirements that the definition is featured by. Here we can adopt what has been proposed by Hilayil for terminology definition, which can be summarized by: 


\subsection{Clarity}

Definition should be reached to the maximum clarity as possible, through accurate definition of concept feature. Such features help determine the boundaries between concepts. The clarity of terminology definition in the lexicon requires attention to the number of issues that enable us to judge such clarity or unclarity. In fact, both requirements overlap and intersect. Despite the approximate meaning between both requirements the clear definition may not be accurate, as the most accurate definition may not be clear. Moreover, we should recognize the difficulty of setting strict boundaries between clarity and accuracy, but there is a degree of common understanding on this. The following examples, explain this perception: Alloush (1984) defines the terminology of "controversy" as:

1) Symmetry between two or more. It is featured by opponency relying on the conflict of ethical values and measures.

2) An attempt centered around specific convictions and satisfactions (Alloush 1984, p.60), whereas he defines the terminology of "Meaning" as:

3) A common terminology that indicates a sign and belongs to symbiosis, where the subject of significance is its study.

4) The meaning of words registered by the "code", according to the criterion.

5) The "impact of meaning" is called on each significance taken from a sign or signs in the speech without possessing a code.

6) It is difficult to search "meaning" in the impressive system of communicative systems. (Alloush 1984, p.155).

Despite that the definition of "Controversy" terminology has more clarity than that of "Meaning", but their clarity space was decreased due to using a number of synonyms within the same definition. The "controversy" is: symmetry and dialogue, while the "meaning" is symbiosis, significance and code.

These definitive constituents, "the synonyms" itself was considered by author of lexicon as stand by itself terminologies:

Symmetry (page 220) Tanathur .(Alloush 1984, p.220)

Dialogue (page 78, 79) Hiwar.(Alloush 1984, pp.78-79)

Sign (page 158) Alamah .Alloush(1984, p.158)

Symbiosis (page 124) Takaful.(Alloush 1984, p.124)

Significance (page 210) Dalalah .(Alloush 1984, p.210)

Code (page 192) Ramz.(Alloush 1984, p.192)

The following example compares the degree of clarity in defining the terminology of "context (Siyaq), in a number of lexicons, as follows:

Table 1. Degree of clarity in defining the terminology of "context" (Siyaq)

\begin{tabular}{|c|c|}
\hline Lexicon & Text \\
\hline Wahbeh, Majdi. & Text: (Nass): \\
\hline $\begin{array}{l}\text { Terminologies of literature. } \\
\text { (1974). }\end{array}$ & $\begin{array}{l}\text { A: The typed or written words that constitute the literal text. } \\
\text { B: Quote parts of the holy books and comment on them in preach. }\end{array}$ \\
\hline & C: Quotation, which is considered the start point for a search or speech \\
\hline Abdulnoor, Jabbor. & Text: (Nass) \\
\hline Literate lexicon. & A: A speech that has only one meaning. \\
\hline (1979). & B: Expanded written or typed speech. \\
\hline Wahbe and Almohandis. & Text: (Nass) \\
\hline $\begin{array}{l}\text { Lexicon of Arabic } \\
\text { Terminologies in language } \\
\text { and literature. } \\
(1984) \text {. }\end{array}$ & The same definition mentioned by Wahbe, Majdi (1974). \\
\hline $\begin{array}{l}\text { Alloush, Saeed. } \\
\text { Lexicon of contemporary } \\
\text { literature terminologies. }\end{array}$ & Text: (Nass) \\
\hline
\end{tabular}


(1985).

Fat-hi, Ibrahim,

Lexicon of literature terminology.

(1986), Opera Word.

Yacoub and Alasi,

Detailed lexicon of

language.

(1987).

Anani, Mohammad,

Modern

Literary

Terminology,

(Study and Dictionary).

(1996).

Lexicon of Basic

Terminology in Symology,

Chandler,

(2002).

Zeitouni, Latif.

Dictionary of Novel

Criticism,

(2002).
1. A terminology that replaces the "literature work", meanwhile we reject the concept of "individual creativity, significance, simulation of reality", where the text becomes an impact of writing.

2. The aims of defining the text, is today the concept of written work as an "expressive truth", where it works on the "radical improvisation" and "multi lines play".

3. The definition of text is derived from its "representative myth", since it is not thought but through its literature and space.

4. Derrida defines the "text" as a number without a fact, or a system of numbers not dominated by the value of truth.

5. Christiffa suggests the definition of "text phenomenon" as opposed to the "text generation" to indicate the text in its literature. The phenomenon of "typed text" is not read without knowing its component:

a. Linguistic statements.

b. Topology of significant verb, where significance becomes this generation.

6. "The Specific Text" is considered by "Tell Kiel Group" as a living power and a formative theory for language.

7. "quotation" becomes a way that convert writing to text.

1. Words of opera or what alike of musical composition.

2.Textual: Adjective belongs to the literature text "Final Verbal Formulation". It also indicates to "Text Criticism".

Not mentioned.

Article of Text and Literary Work.

In his article "Text Theory", Roland Bart says that literary work is a complete thing, a computable one, and a physical thing that occupies space. But "the text is a systematic field". He adds: "the literary work is what is caught in our hands, and the text is what is existed in language.

Article: Text

This terminology is used in general to indicate any thing that we can read to find the meaning. Some theorists regard the world as a "social text". Although this term seems to prefer the written texts, because it depends on the written word, and can refer a center outside it that ensures the validity of meaning and guarmtees it. However, for most sinologists, it is a system of signs (words, images, sounds and/or gestures). The text is created or interpreted by reference to special conventions, interconnected to a specific type and through communication media or one of its means. This term is frequently used to refer to the registered "written" text which does not depend on users to achieve existence. The use of the term in this meaning excludes the unregistered speech. The text is a product of cognitive representation processes. It also impositions its makers and readers or recipients. (See: Self [Athaat]. The reader tends to focus attention on what represented cognitively in the text, rather concentrating on the processes of implied cognitive representation, which the text was created through, (These are the processes that usually seem transparent).

Article: Text (Nass).

The linguistics describes that word (Text) as the sum of words subject to analysis. The text, in this sense, is synonymous to the lingual text corpus. Hjelmslev refers to "text word" as verbal or written, expanded or concise, old or new. The word "Stop: Qiff" is a text, and the whole novel is a text. The text may be similar to a statement, but it remains a separate system than language system, despite their analogous and similarity. Rolan Bart compares the text to sign. Perhaps the most prominent epistemological definition of the text is what was introduced by Julia Kristiva in that "The text is a tool that begs and rearranges the language to create 
Almotqan.

Dictionary of Modern Linguistic and Literature Terminology.

Hijazi, Samer, (2003).

Raghib, Nabil.

Encyclopedia of Literature Theories,

(2003).

Nassar, Nawaf. Literary Dictionary, (2007).

Boughra, Nyman.

Basic Terminology in Textual Linguistics and Speech Analysis (Study of the Lxicon), (2009). a relationship between the direct epigraphic speech and different previous as well as contemporary statement.

Article: Text (Nass).

It is any historical product of writing that was organized upon start and finish (beginning and end), or all that shows ability to build an internal structure characterized by a degree of durability that enables it to resist the previous linguistic, psychic and social structure. The writing is characterized by openness, liquidity and power against external influences.

Article: Textualism: Alnassiyah.

The literary text is a productive process that relies on differentiation. Text is not a closed structure, and it produces its special rules by force. Bart says that "we know that any text is not lines of words to give eternal and theological agreedupon meaning, but it is a multi-dimensional space, in which other texts are mixed and collided, whether previous or synonymous texts for the new text. "The text is just a texture of quotes derived from innumerable sources of culture". This evolution, initiated by Julia Christiva and confirmed by Roland Barthes, in rejecting the idea of a closed text, has paved the way to Jack Derrida to make a deep track for his theory of deconstructionism since the late 1960s.

Article: Text (Nass)

1. Original written text whether hand written or printed, such as the text of novel or play.

2. Speech of a book that is distinct from other pictures, illustrations or comments.

Article: Text: Annass

A comprehensive unit that consists of different parts at the level of horizontal grammar, and at the level of vertical semantics. This means that the text is a main unit that doesn't include a larger unit. The first (horizontal) level is composed of smaller text units of grammar, while the second (vertical) level is composed of holistic perceptions that are linked to the semantic coherence. Therefore, when we analyze the text, it is necessary to construct a holistic theory derived from the simple theories that combine all levels. The text, in the traditional concept, is not left through its internal components, if we judged the function it performs.

The initial analysis of these definitions indicates that explanation is the most important criterion of (clarity) of the "terminological definition". Where there is an interest in explanation and analysis, the definition becomes clearer. Most of the mentioned definitions focused on explaining the term of the text and analyzing its horizontal and vertical levels, as mentioned in the Basic Terminology of Linguistic Text and Analysis of Speech Dictionary; besides its verbal and written styles, and structural forms (words, pictures, images, sounds and gestures) as shown in the Lexicon of Semantical Basic Terminology and Dictionary of Terminology of Novel Criticism.

The second important criterion in increasing the clarity of the term is the inclusion of cognitive references that have added specific characteristics to the definition. We note that a number of these lexicons have focused on specific critics who added specific meanings to the terminology of text in a famous critical works, such as Tel Keil Groups, Julia Christiva, Rolan Barthes, Hjlmesliv and Jack Derrida and others.

Finally, "simplification of information" is a basic criterion of clarity of definition, "text" is "original written speech whether manuscripted or printed". We say: the text of the novel or the text of the play, a speech from a book, distinct from pictures, explanations and comments, as mentioned by the literary dictionary by Nawaf Nassar.

\subsection{Accuracy}

In requirements of the second condition: the accuracy, the inaccurate definition causes technical and epistemological confusions that spoil terminology. The most prominent facetted of definitive accuracy are:
a) A: Accuracy of Translation;
b) B. Accuracy of mispositioning;
c) C: Accuracy of representations;
d) D: Accuracy of measurement to similar requirements/ the boundaries. 
As for the accuracy of translation, it is an issue related to the terminology borrowed from the western critique, especially English and French critique. The researcher doesn't need to repeat the translating dilemma in the critical and literary requirements, but we remind of what had happened in the Arab heritage of misunderstanding and miscomprehension of accuracy when translating the book of Aristole: Art of poetry. This is sufficient to indicate the importance of such issue.

Perhaps the accuracy of translation is needed more in translating modern terminology, such as these requirements of perspectives and sects of literature and criticism where some have developed more than others, while some sects contradicted with others. Let us take the term Intertextuality (Attannass), where the problem of definition accuracy was not only Arabian, but the European studies suffered this problem of inclusion the concept, definition and identity of the term.

This problem is based on the reliance of European critics on different ideologies, philosophies, and theories when they were involved in handling of the term convergence and its coordinates (Almogheith 1997, p.81).

Such involvement stimulates several questions about the definitions, which covered this term in the critical studies and terminology lexicons, when introduced in isolation of these ideologies, philosophies and theories, and represented influencing cultural environments in guiding the term towards certain definitions.

In this respect, the lexicon of Modern Literary Terminology in defining the "intertextuality", mentions the book "Desire in Language", which the author translated from Julia Christiva, that he deplored the misunderstanding of the term in general, denying the impact of a writer on another and the idea of literary work. He assured that the intended issue was "exchange of sign order between texts or replacing a style approach by another" (Anani 1996, p.47). It seems that indication to misunderstanding by Rodiez reflects a part of what is meant by "accuracy of definition".

The researcher believes that the definition of "Modernity" term puts us in front of a clearer picture on the impact of different philosophies and ideologies on the accuracy of definition". If the "term of Modernity" is clear in some aspects of science and technology, and associated with the thought, sociology, economics and politics, it remains covered in vagueness when used with language and literature.

Some of those who pretend to be knowledgeable of it and its application are still using vague verbs in explaining it, where these ambiguous meanings indicate the thing and its opposition. After some efforts the reader will lose understanding, where those writers seek to clarify the ambiguity by including other synonyms like: modernization, renovation, regeneration and development (Alasad 2006, p.128)

But the search in translation accuracy by its art side is represented by a new way of defining the term of Free Poetry that corresponds to the English free verse and the French Verse Libres since 1910, when Amin Raihani used it. It is known as the prose poetry which Raihani had the privilege to lead it (Altami 1998, p.200). Raihani, in his collection of poems called "the Call of Vallies", said that "this type of poetry is verse libre in French and free verse in English, since this what has come to the peak of western literature, especially of Americans and British poets (Altami 1998, p.200).

Nazik Almaleikah also used this term to define the new form of poetry which she led in the 1940s and 1950s, so she called it the free poetry (Almala'ikah 1974,35-37). But Jabra Ibrahim Jabra rejected this proposition, because "the free poetry is a poetry free of symmetry and rhyme, as written by the English poet Walt Wittman, and Arab poets like Mohammad Almaghout and Tawfeeq Alsayigh and others (Jabra 1967, p.18).

These differences and discussions were reflected on the contents of terminological lexicons on the definition of free poetry. Here we can mention four lexicons which included this term, two of them relied on the English term "Free Verse" where authors of the "lexicon of Arabic Terminology in Language and Literature" said that "this term denotes to the poetry which is not constrained by rhyme and rhythm which was created by French poet Lafontaine in the $17^{\text {th }}$ century thorough the poems of "Animal Tales".

But the golden age of free poetry in France began in 1886 when the symbolic perspective flourished and relied on naturalization of sounds instead of rhythm. It can be said that most contemporary poetry in many countries had been converted to free poetry, for example Salah Abdul Sabour and Abdul Muti Hijazi in Arabic poetry (Wahbah 1984, p.213). Nawaf Nassar mentioned that this poetry "is that poetry free of rhythm and rhyme, so it is easier than the traditional poetry (Nassar 2006, p.110).

In the first lexicon, it eliminated the accuracy of definition when it considered the poetry of Salah Abdal Sabour and Ahmad Abdul Muti Hijazi as free poetry despite that their poems are rhymed. Such accuracy elimination by Nassar in defining the term is based on inaccurate judgement which says that "writing free poetry is easier than writing traditional poetry", since he couldn't prove his argument (if he meant the good poetry). 
As for the lexicons that adopted the French requirements of "verse libre", Majdi Waba stated that "French free poetry is a kind of poetry that is not adhere to the rules of well-known performances like poetic tales of Lafontaine. The term was especially pronounced on the poetry of some symbolic movement poets, which was characterized by the attempt to imitate the musical tones in the traditional poetry, with focus on the pitch which was not recognized in the French poetry previously. The symbolic poetry adopted some features of traditional poetry and ignored other features. Gustav Kahn was one of the pioneers of French free poetry (Wahba 1984, p.599).

Ibrahim Fat-hi defines the free poetry as a "French expression also known as polyphonic prose. Such poetry is distinct from the traditional poetry in that its vocal style does not follow regular rhythm and rhyme and depends on the rhythm more than frequent movements in the traditional poetry. The free poetry is an old form of literature in the Psalms of David and Solomon in the Old Testatement. There are also many poems of free poetry like Walt Whitman and Karl Sandborg.( Fat-hi 1986, p.216).

It is noted that both definitions are accurate since they do not mix the traditional and free poetry. It hadn't been free of rhythm, but it had adopted a different musical system than the tone system. The accuracy of representation is expressed through what is included in the definition of illustrative examples. We can refer to some terminology in lexicons such as:

Term of Beauty (with protest of the researcher against considering this word as a term)

It is a feature desired by the poetry and mind through the harmony between color and form. Abu Hayyan Al tawhidi, the beauty philosopher, raised the problem of aesthetic perception by the best way (Nassar 2006, p.63). Such definition is not accurate enough to let $\mathrm{Al}$ tawhidi as a philosopher and quote his sayings in defining the aesthetic perception.

In defining the column of poetry, Nassar stated that "It is the most famous meaning in writing the poetry according to the traditions with rhythm and rhyme. He added "The Arab traditional poetry responded to the development of free poetry which was adopted by the new poets, after a time of sarcasm and criticism by youth. We feel that these developmental movements were created as a response to a desire for renovation of the old patterns, not to get rid of them (Nazik, issues, p. 13). The traditional poems are still dominant for its influencing music, rhythmed tone and its attracting beauty Khafaji, 2001/8, p. 193; Nassar 2006, p.144)

What is noted here by the researcher is that the author of lexicon adopted opinions and sayings different than the true meaning (of the traditional poetry), where it was better for the author to refer to Marzouki; (died $421 \mathrm{~h}$ ), which this term was created by him. The author also had to refer to "Sharhu Diwanil Hamasah" in which the introduction tells us that the Arabs were trying to grasp the honor of meaning and its validity and the correct words that aim at pointing at the main idea. For the combination of these reasons Arabs accumulated proverbs, wisdom and poetry as well as the description and structures of the verses with metaphors that select the best rhythm and compatibility of verb to meaning with suitable rhythm and rhyme. There are seven styles of the traditional poetry that each style has its own measures (Almarzouqi 1951, p.89)

The author was able to refer to any source of criticism in Arab literature to track this term and its development. Some researchers discovered "the quoting from Al Marzouqi rules and measures that he obtained from Ibn Tabatib bin Ja'afar, Alqadhi Al jurjani and Al-Almidi .(Bakkar 1984, p.8)

As for the precision of definition, or its uniqueness and multiplicity, we find for some requirements one uniform definition while other requirements have several definitions. Therefore, the problem of multiple definitions for one term needs more attention.

When we read the term "structure" we find common agreement among lexicons but several definitions despite the fame of this term and its historical origins. Majdi Wabah defines the "structure" as mentioned by the American critic, John Ransom in that "The literary work is composed of two elements, the structure and the form, where structure means the general meaning of the literary work and the message conveyed by this work in details to the reader and expressed in various ways. (Wahbah 1984, p.540). Saeed Alloush defines the same term as:

1) A transforming system which has rules and is enriched through its own varied transformation within its boundaries or seek help from external elements.

2) The structure consists of three components: wholeness, transformation and self-modification.

3) The structure is an abstract concept: forms are dominated by ways of assimilation. (Alloush 1984, p.52)

What we find from previous two definitions represents a great gap between them. What Wahbah mentioned in connecting the structure to the meaning has no relationship with the definition of Alloush.

Perhaps the last note on the accuracy of definition is that related to clarifications of aspects of knowledge that the 
definition belongs to, or unclarification.

In the lexicon of literary Terminology the "heuristic" is defined as "an activity or a set of activities or actions that stimulate the interest and urge the continuous search by the person to discover the facts for himself" . (Fat-hi 1986,76). The author didn't identify the epistemological domain of the definition whether philosophy, literature, interpretation or mysticism etc. while in other cases he identified the epistemological domains, as in the lexicon of literature and language terminology, where the author of defined the term "plural" as multiple genres share one common thing, as what Abu $\mathrm{Al}$ atahiyah had said (died $211 \mathrm{~h}$ ):

"The youth, time and wealth... spoil the person severely", while in the lexicon of "Annahwoul arabi" the term "plural" means more than two and doesn't need sympathetic ones (Wahbah 1984, p.135).

In defining the term "Nature", we find many guidelines (in the history of thought, Christian Theology, Aesthetic, and poetry (Wahbah 1984,235). When the definitions of the term are many we must identify its epistemological domains as an issue of accuracy of definition.

\subsection{Completeness}

Multiplicity of concepts is an important feature of terminology. Therefore, definitions should not represent one meaning or perspective, and should not be biased to one specific perspective, where it may lead to vague or incomplete meaning. (Helayil 1992, p.5). The "completeness" requirement in the definition is varied upon the diversity of the literature and criticism Terminology Lexicons and variety of its characteristics, since the definition completeness in the encyclopedia lexicons, such as: Encyclopedia of Criticism Terminology by Abdul Wahid Lo'lo'ah; Lexicon of Guidlines of literary critic by Roayily and Baziei; Encyclopedia of Literature Theories by Nabil Raghib and other lexicons, will be different than that of general literature and criticism terminology lexicons, which collect all types of literature and criticism, poetry, eloquence whether in poetry or prose in old and present times such as: Lexicon of Literature Terminology by Majdi Wahba; The Detailed Dictionary of Language and Literature by Yaqoub and A'assi; Literary Dictionary by Jabbour Abdonnour and others, specialized lexicons of comprehensive nature.

The correct definition completeness in some of these lexicons may not apply to another one, especially the dedicated lexicons in one field of literature or criticism only such as: Lexicon of Basic Terminology in Semiotica by Chandlier; Lexicon of Semiotica Terminology by Martin and Ringham, Lexicon of Narrative Terminology by Gerald Prince and Lexicon of Novel Criticism Terminology by Latif Zaitoun, and other lexicons.

We mean by the definition completeness that "definitions should not represent one meaning or perspective, and should not be biased to a particular perspective or language, otherwise it will lead to the to a vague or incomplete correspondent".(Khattabi 1998, p.31).

No doubt that examples of the term whose definitions vary upon multiple intellectual environment or time and space frames are many. Perhaps the clearer definition of the term of "comparative literature", where its scholars consider that its definition in the context of American literature differs than that of French literature, or other types of literature in different cultures.

But the researcher encounters a term definition in some lexicons that doesn't match this aspect. He doesn't know which view it follows, and how does it reconcile among different perspectives to conclude one unified definition, meanwhile it is in fact different.

We can refer to the definition of "Comparative Literature Term" in the "Literature Dictionary" by Nassar who defines it as "the study of similarity and symmetry between the literature of two nations or more, where the literature is a manifestation of public interest and activities of all nations and races in the world. Therefore, the scholars attempt to clarify specific literature works through cultural symmetries or contradictions, besides studying the impact of each literature on other literatures' (Nassar 2006, p.11).

It is noteworthy that this definition presents the concept of comparative literature from one viewpoint that restricts the concept of literary comparison on the study of literary similarity between the two nations or ore without considering the other viewpoints. The comparative literature has different concepts according to different perspectives, while there is no one concept agreed upon between them as we explain later.

The grasp of integrated holistic definition is an attempt requires us to "focus on the history of comparative literature term and try to identify its meanings in the principal languages since it has been a subject of considerable controversy, argument, explanations and misunderstanding. We can't identify its meaning and content without applying it" (Willick 1987, p.304). This is the task of lexiconist and dictionary author, since he presents the knowledge in neutral and objective focus, equates other viewpoints and opinions that defined the same term, and 
provides more benefit to researchers and readers.

The term of "comparative literature" has now three meanings by the academics. The French perspective defines it as "the study of historical relationships among literatures", while the American viewpoint considers it as "the study of common attitudes of arts and literatures among the western group of literature", while other perspectives consider it as "the mutual impacts among literature, arts and knowledge" (Ayad 1993, p.80). These perspectives were not stated in the lexicon.

The researcher finds these details about the "definition completeness" in a dictionary like the "Guidelines for Literary Critic", which considers that the feature of American perspective in defining the term is "the belief of literary phenomenon holiness in the comparative literature against the French perspective.

The most prominent scholars who represent the American viewpoint is Renee Willick who, in the mid of twentieth century, criticized strongly some methodological concepts and procedures, such as the artificial distinction between subject and approach, the mechanical concept of sources and influences, and the tendency towards the cultural nationalism.

In this respect, there is the implied "crisis of the comparative literature", as Willick called it. He calls for overwhelming this crisis, through the elimination of the distinction between "general literature and comparative literature" and other created concepts and procedures associated with the emergence of the comparative literature in France, especially with the founders of the "Reveue de literature comparatif", Van Tegem and Baldonschberger. But the difference between European perspectives didn't eliminate the accord among them in the recent years with the common denominators". (Alroayli 2007, p.30).

\section{Conclusion}

Terminology definition requires understanding its requirements in order to be meaningful enough to lead to the purpose of this terminology placement. Achieng a kind of consensus on such definition among scholars needs to realize the definition requirements and features. Literature should that clarity, accuracy and completeness are the key features that blueprint adequate terminologies requirements. Clarity feature helps determine the boundaries between concepts. The clarity of terminology definition in the lexicon requires attention to the number of issues that enable us to judge such clarity or unclarity. Since achieving clear communication without obscurity is one of the most important goals of the language, accuracy will be a must and principal requirement. Furthermore, the boundaries between concepts should be strictly defined. Multiplicity of concepts is an important feature of terminology. Therefore, definition completeness should not represent one meaning or perspective, and should not be biased to one specific perspective, where it may lead to vague or incomplete meaning.

\section{References}

Al Marzooqi, A. (1951). Sharhu Diwan Al hamasah. Edited by: Ahmad Ameen and Abdussalam Haroun. Vol. 1. Cairo.

Al Roaili. M \& Albaziei, S. (2007). Guide of Literary Critic. Almarkaz Althaqafi Alarabi. Beirut. ed. 5.

Alasad, N. (2006). Tahqiqat Adabiyah. 1st. ed. Publications of Amman Municipality. Amman.

Aljilali, H. 1999. Definition Techniques of Contemporary Arabic Lexicons. Arab Federation of Writers. Damascus.

Alloush, S. (1984). Lexicon of Contemporary Terminology. 1st. ed. Almaktabah Al Jamiyah. Casa Blanca.

Almugheith, T. (1997). Term of Teetotalism and its Derivatives in the Field of Translation to Arabic Language. Majallat Turjuman. Vol. 6. No. 2.

Anani, M. (1996). Modern Literary Terminology: English Arabic Study and Dictionary. 1st. ed. Maktabat Lubnan. Beirut.

Arriheni, A. (1955. Call of Vallies. Dar Alrihani. Beirut.

Attami, A. (1998). The Problem of Modern Poetical Terminology. Majallat Alamat. Part 30. Vol. 8.

Ayad, Si. (1993). Literary and Critical Sects (Schools) of Arabs and Western. A'alam Al-Ma'rifah. No. 177. Kuwait.

Bakkar, Y. (1984. Issues in Criticism and Peotry. Dar Alandalus. 1st. ed. Beirut.

Fat-hi, I. (1986). Literary Terminology Lexicon. Almoa'assatul Aabiyah Lilanashireen Almottahidn. Cairo.

Hillayil, M. (1992). Towards a Systemic Plan to Write Dual Dedidicated Lexicon. Majallat Al Mo'ajamiyah. No. 8

Isteif, A (1999). Crisis of Criticism Terminology in the Contemporary Arabic Culture. Majallat Al-aadab. No. 5. 
Jabra, J. (1967). The Eight Travel. Almaktabatul Asriyah. Beirut

Jadd, Izzat. 2002. Contemporary Critical Term between Egyptians and Morrocan. Majallat Fosoul. No. 62.

Khattabi, Mohammad. (1998). The Modern Terminological Article in "Al Morjan Al Mofassal in Aladab by Mohammad Altontanji". Majallt Allisan Alarabii.No. 46.

Nassar, N. (2006). Literary Dictionary. 1st. ed. Dar Ward. Amman

Shahin, Abussabour. (1986). Arabic: The Language of Science and Technology. Dar Al I'tisam. Cairo. 2nd ed.

Wahbah, M \& Almohandis, K. (1984|). Lexicon of Arab Terminology in Language and Literature. 2nd. ed. Maktabat Lubnan. Beirut.

Willick, R. (1987). Critical Concepts. A'alam Al-Ma'rifah. No. 11 Kuwait.

Zeidan, M. 1985. Language Philosophy. Dar AlNahdhah Al Aabiya. Beirut.

\section{Copyrights}

Copyright for this article is retained by the author(s), with first publication rights granted to the journal.

This is an open-access article distributed under the terms and conditions of the Creative Commons Attribution license (http://creativecommons.org/licenses/by/4.0/). 